\title{
Inhomogeneous distribution of defect-related emission in Si-doped AIGaN epitaxial layers with different Al content and Si concentration
}

\author{
Satoshi Kurai, ${ }^{1, a)}$ Fumitaka Ushijima, ${ }^{1}$ Hideto Miyake, ${ }^{2}$ Kazumasa Hiramatsu, ${ }^{2}$ \\ and Yoichi Yamada ${ }^{1}$ \\ ${ }^{1}$ Department of Material Science and Engineering, Yamaguchi University, 2-16-1 Tokiwadai, Ube, \\ Yamaguchi 755-8611, Japan \\ ${ }^{2}$ Department of Electrical and Electronic Engineering, Mie University, 1577 Kurimamachiya, Tsu, \\ Mie 514-8507, Japan
}

(Received 13 December 2013; accepted 21 January 2014; published online 4 February 2014)

\begin{abstract}
The spatial distribution of luminescence in Si-doped AlGaN epitaxial layers that differ in $\mathrm{Al}$ content and $\mathrm{Si}$ concentration has been studied by cathodoluminescence (CL) mapping in combination with scanning electron microscopy. The density of surface hillocks increased with decreasing Al content and with increasing Si concentration. The mechanisms giving rise to those hillocks are likely different. The hillocks induced surface roughening, and the compositional fluctuation and local donor-acceptor-pair (DAP) emission at hillock edges in AlGaN epitaxial layers were enhanced irrespective of the origin of the hillocks. The intensity of local DAP emission was related to $\mathrm{Si}$ concentration, as well as to hillock density. CL observation revealed that DAP emission areas were present inside the samples and were likely related to dislocations concentrated at hillock edges. Possible candidates for acceptors in the observed DAP emission that are closely related in terms of both $\mathrm{Si}$ concentration and hillock edges with large deformations are a $\mathrm{V}_{\text {III }}-\mathrm{Si}_{\text {III }}$ complex and $\mathrm{Si}_{\mathrm{N}}$, which are unfavorable in ordinary III-nitrides. (C) 2014 AIP Publishing LLC. [http://dx.doi.org/10.1063/1.4864020]
\end{abstract}

\section{INTRODUCTION}

$\mathrm{Al}_{x} \mathrm{Ga}_{1-x} \mathrm{~N}$ ternary alloys are attractive candidates for light emitters or detectors operating in the ultraviolet spectral region, due to their direct band gap energy between 3.440 (Ref. 1) to $6.015 \mathrm{eV}$ (Ref. 2) at room temperature. It is well known that Si doping into an $\mathrm{Al}_{\mathrm{x}} \mathrm{Ga}_{1-\mathrm{x}} \mathrm{N}$ epitaxial layer drastically changes its structural, electrical, and optical properties through phenomena, such as dislocation inclination, ${ }^{3}$ nano-mask effect, ${ }^{4,5}$ changes in electric conductivity, ${ }^{6,7}$ cathodoluminescence (CL) intensity enhancement, ${ }^{8}$ introduction of point defects, ${ }^{9}$ and changes in optical polarization along with variation in strain state. ${ }^{10,11}$ For the fabrication of high-efficiency devices, it is important to investigate in detail the effects of Si doping on AlGaN ternary alloys. The microscopic distribution of luminescence in Si-doped AlGaN ternary alloys is also an important topic of research.

Recently, scanning near-field optical microscopy in combination with photoluminescence (SNOM-PL) has attracted considerable attention as a practical technique for studying optical inhomogeneities owing to its high spatial resolution below the diffraction limit of light and has been used for evaluating the microscopic luminescence of $\mathrm{AlGaN}$ epitaxial layers. ${ }^{12,13}$ However, the excitation wavelength available in SNOM-PL and the relative $\mathrm{Al}$ content range to which it is applicable are limited to around $258 \mathrm{~nm}$ and about 0.50 , respectively, due to damage to the optical fiber used as a SNOM probe. From this point of view, CL in combination with scanning electron microscopy (SEM) is another

${ }^{\text {a)} E m a i l: ~ k u r a i @ y a m a g u c h i-u . a c . j p ~}$ technique suitable for detecting optical inhomogeneities in $\mathrm{AlGaN}$ with high spatial resolution.

We investigated the microscopic distribution of optical emission in Si-doped AlGaN alloys with different Si doping concentration and found that the density of surface hillock structures and local donor-acceptor-pair (DAP) emission at hillock edges increased with increasing $\mathrm{Si}$ doping concentration. ${ }^{14}$

In this paper, we report the spatial distribution of luminescence in Si-doped AlGaN epitaxial layers with different Al content by CL mapping in combination with SEM and discuss the effects of Si doping on the luminescence distribution in $\mathrm{AlGaN}$ epitaxial layers with different $\mathrm{Al}$ content at a fixed Si concentration as well as ones with different Si concentration at a fixed $\mathrm{Al}$ content.

\section{EXPERIMENTS}

The sample sets used in this study were $0.8 \mu \mathrm{m}$ thick Si-doped $\mathrm{Al}_{x} \mathrm{Ga}_{1-x} \mathrm{~N}$ epitaxial layers with relative $\mathrm{Al}$ content from 0.42 to 0.73 and $\mathrm{Si}$ concentration of $3.7 \times 10^{17} \mathrm{~cm}^{-3}$, and $0.8 \mu \mathrm{m}$ thick Si-doped $\mathrm{Al}_{x} \mathrm{Ga}_{1-x} \mathrm{~N}$ epitaxial layers with almost same relative $\mathrm{Al}$ content $(0.60-0.63)$ and $\mathrm{Si}$ concentration of $3.7 \times 10^{17} \mathrm{~cm}^{-3}$ to $3.7 \times 10^{18} \mathrm{~cm}^{-3}$. A nominally undoped $\mathrm{Al}_{0.66} \mathrm{Ga}_{0.34} \mathrm{~N}$ epitaxial layer was also included in the latter sample set. Each Si-doped $\mathrm{Al}_{x} \mathrm{Ga}_{1-x} \mathrm{~N}$ epitaxial layer was grown on a c-plane sapphire substrate by low-pressure metalorganic vapor phase epitaxy (LP-MOVPE), following the deposition of a $0.8 \mu \mathrm{m}$ thick AlN buffer layer and a $0.2 \mu \mathrm{m}$ thick Al-rich AlGaN intermediate layer (IML). ${ }^{8}$ The Si concentration of the Si-doped AlGaN epitaxial layers was estimated by secondary ion mass spectroscopy (SIMS). The 
TABLE I. Summary of sample characteristics. All samples were $0.8 \mu \mathrm{m}$ thick $\mathrm{A}_{1 x} \mathrm{Ga}_{1-x} \mathrm{~N}$ epitaxial layers having different amounts of Si deposited on sapphire (0001) substrate with $\mathrm{AlN}(0.8 \mu \mathrm{m})$ and $\mathrm{AlGaN}$ intermediate layers $(0.2 \mu \mathrm{m})$. Even in the worst case, relative Al content contains the uncertainties only in the range of \pm 0.01 . Detection limit of SIMS measurement for $\mathrm{Si}$ concentration is less than $1 \times 10^{16} \mathrm{~cm}^{-3}$.

\begin{tabular}{lcc}
\hline \hline Sample set & 1 & 2 \\
\hline Relative Al content $x$ & $0.42,0.49$, & $0.60-0.63$ \\
& $0.60,0.73$ & \\
Si concentration $\left(\mathrm{cm}^{-3}\right)$ & $3.7 \times 10^{17}$ & Nominally undoped \\
& & $(x=0.66), 3.7 \times 10^{17}$, \\
& $7.4 \times 10^{17}, 1.9 \times 10^{18}$, \\
& $3.7 \times 10^{18}$ \\
\hline \hline
\end{tabular}

Al content was measured by asymmetric reciprocal space mapping (RSM) around the reciprocal lattice points (RLPs) of the (105) reflection of $\mathrm{Al}_{\mathrm{x}} \mathrm{Ga}_{1-\mathrm{x}} \mathrm{N}$ by using a four-circle diffractometer (X'Pert-MRD, Philips Co., Ltd.). ${ }^{11}$ The RSM obtained in this work was referenced to the (1 1112$)$ RLP position of $\mathrm{Al}_{2} \mathrm{O}_{3}$, which was used as the substrate. The characteristics of the sample set are summarized in Table I.

CL mapping measurements in combination with SEM were carried out with a CL system (Mono CL2, Oxford Co., Ltd.) attached to a microscope (S-4300SE, Hitachi Co., Ltd.) at an acceleration voltage of $3.0 \mathrm{kV}$ and a sample current of around $150 \mathrm{pA}$. The spatial resolution of CL mapping estimated from the acceleration voltage is about $150 \mathrm{~nm}$. ${ }^{15}$ The spectral resolution was $\pm 0.90 \mathrm{~nm}$. The measurement temperature was set to $80 \mathrm{~K}$.

\section{RESULTS AND DISCUSSION}

Figure 1(a) shows SEM images of the AlGaN epitaxial layers with different relative Al content. Smooth surface morphologies were observed for the AlGaN epitaxial layers with high relative $\mathrm{Al}$ content, and hexagonal hillocks with a diagonal of several micrometers appeared with decreasing the $\mathrm{Al}$ content.

Figure 2 shows the density of hexagonal hillocks in the AlGaN epitaxial layers as a function of relative $\mathrm{Al}$ content. The hillock density monotonically decreased with increasing relative $\mathrm{Al}$ content, and hillocks were not observed for relative $\mathrm{Al}$ content higher than about 0.73 . The relaxation ratio $R$ of the same sample sets of AlGaN epitaxial layers was evaluated by precise RSM, and it was found that the AlGaN epitaxial layers with relative $\mathrm{Al}$ content higher than about 0.7 were coherently grown on the underlying AlN substrate. ${ }^{11}$ This trend was similar to the relation between hillock density and relative $\mathrm{Al}$ content, indicating that the formation of hillocks in the AlGaN epitaxial layers with low relative $\mathrm{Al}$ content is related to the relaxation of compressive strain arising from the increase in lattice mismatch between the underlying layers.

Figure 3(a) shows SEM images of the $\mathrm{Al}_{0.61} \mathrm{Ga}_{0.39} \mathrm{~N}$ epitaxial layers with different $\mathrm{Si}$ concentration, where the density of hexagonal hillocks increased monotonically with increasing Si concentration. ${ }^{14}$ The density of hexagonal hillocks in AlGaN epitaxial layers as a function of Si concentration is shown in Fig. 2. Clearly, hillock density decreased with decreasing Si concentration, and hillocks virtually disappeared at a $\mathrm{Si}$ concentration of $5 \times 10^{17} \mathrm{~cm}^{-3}$. Conceivably, hillock formation is also caused by strain because compressive strain is released at a $\mathrm{Si}$ concentration above around $4 \times 10^{17} \mathrm{~cm}^{-3}$ in $\mathrm{Al}_{0.61} \mathrm{Ga}_{0.39} \mathrm{~N}$ epitaxial layers. ${ }^{11}$ However, the change in strain caused by varying the Si concentration was found to be much smaller than that caused by varying the relative $\mathrm{Al}$ content. These results indicate that the mechanism of hillock evolution has at least two origins, namely relaxation of

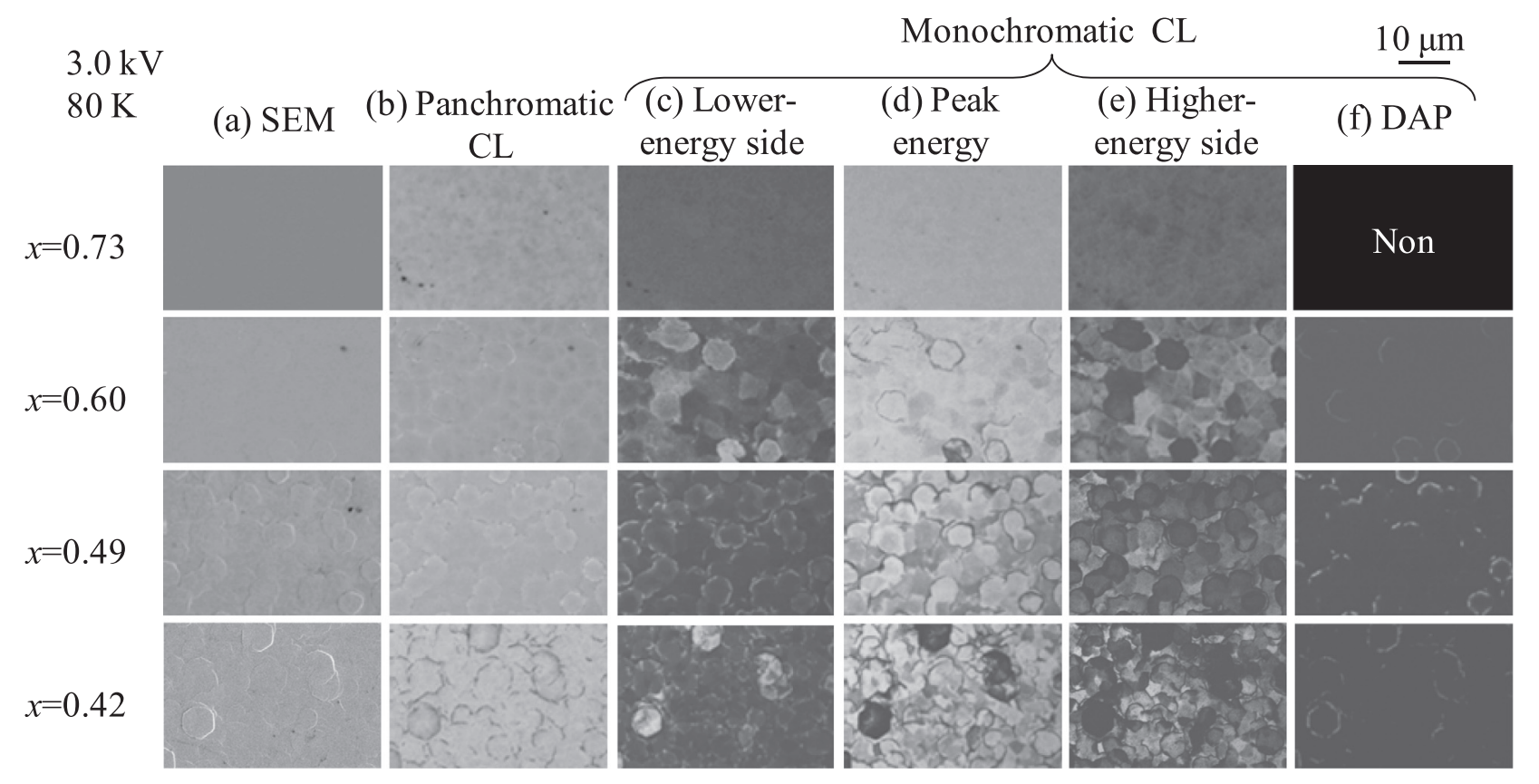

FIG. 1. (a) SEM images; (b) panchromatic CL images; monochromatic CL images obtained at the (c) lower-energy side, (d) peak energy, and (e) higherenergy side of the NBE emission; and (f) DAP emission observed in Si-doped $\mathrm{Al}_{\mathrm{x}} \mathrm{Ga}_{1-\mathrm{x}} \mathrm{N}$ epitaxial layers with different relative $\mathrm{Al}$ content at $80 \mathrm{~K}$. The $\mathrm{Si}$ concentration was $3.7 \times 10^{17} \mathrm{~cm}^{-3}$. 


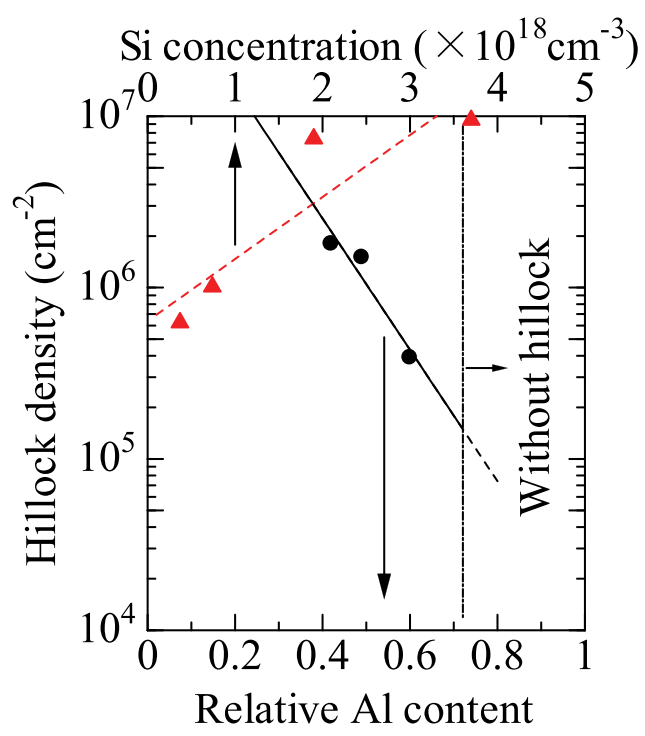

FIG. 2. Hillock density in AlGaN epitaxial layers as a function of relative $\mathrm{Al}$ content (solid circles) and $\mathrm{Si}$ concentration (solid triangles). No hillocks were observed in the $\mathrm{Al}_{0.73} \mathrm{Ga}_{0.27} \mathrm{~N}$ epitaxial layer, as clear from Fig. 1(a).

compressive strain in $\mathrm{AlGaN}$ epitaxial layers and structural changes induced by $\mathrm{Si}$ incorporation (such as an anti-surfactant effect or a nano-mask effect). ${ }^{4,5}$

Figures 1(b) and 3(b) show panchromatic CL images of $\mathrm{AlGaN}$ epitaxial layers with different relative $\mathrm{Al}$ content and with different $\mathrm{Si}$ concentration taken at $80 \mathrm{~K}$, respectively. The observation positions were identical to those in the corresponding SEM images. Spatial distribution similar to that of the hillock structures in SEM images was observed in the panchromatic CL images of AlGaN epitaxial layers with relatively low relative $\mathrm{Al}$ content and in the layers with relatively high Si concentration. The hillock edges were dark in the panchromatic CL images, with bright regions observed near the dark regions. Interestingly, these observations indicated that the panchromatic CL distribution related to the hillock distribution did not depend on the origin of the hillocks. The dark hillock edges in the panchromatic CL images indicate the presence of many defects at hillock edges, which are introduced during the coalescence of grains and act as nonradiative recombination centers. To discuss the distribution of emission in the AlGaN epitaxial layers with different relative $\mathrm{Al}$ content and $\mathrm{Si}$ concentration, we obtained CL spectra and monochromatic CL images.

Figure 4 shows the CL spectra of (a) AlGaN epitaxial layers with different relative $\mathrm{Al}$ content and (b) $\mathrm{AlGaN}$ epitaxial layers with different $\mathrm{Si}$ concentration at $80 \mathrm{~K}$. The vertical axis denotes the logarithmic CL intensity. The CL spectra showed dominant near-band-edge (NBE) emission. Peak energy of NBE emission shifting toward higher energy with increasing relative $\mathrm{Al}$ content is explained by normal band gap shift corresponding to the increase in relative $\mathrm{Al}$ content. The slight differences between peak energy of NBE emission around $4.9 \mathrm{eV}$ in Fig. 4(b) are due to small differences in relative $\mathrm{Al}$ content. As clear from Fig. 4(b), new emission lines appeared below the peak energies of NBE emission with increasing $\mathrm{Si}$ concentration. The origin of these emission lines is attributed to Si-related DAP emission; ${ }^{14}$ indeed, DAP emission lines were not observed in the nominally undoped AlGaN epitaxial layer. Weak DAP emission below the peak energy of NBE emission was also observed in the Si-doped AlGaN epitaxial layers with relative $\mathrm{Al}$ content of $0.42,0.49$, and 0.60 (Fig. 4(a)). DAP emission was not observed in the Si-doped $\mathrm{AlGaN}$ epitaxial layer with relative $\mathrm{Al}$ content of 0.73 . The energy of the $\mathrm{Si}$-related DAP emission band increased with increasing relative $\mathrm{Al}$ content. The energetic distances between the NBE emission and the DAP emission for the Si-doped AlGaN epitaxial layers with relative $\mathrm{Al}$ content of $0.42,0.49$, and 0.60 were

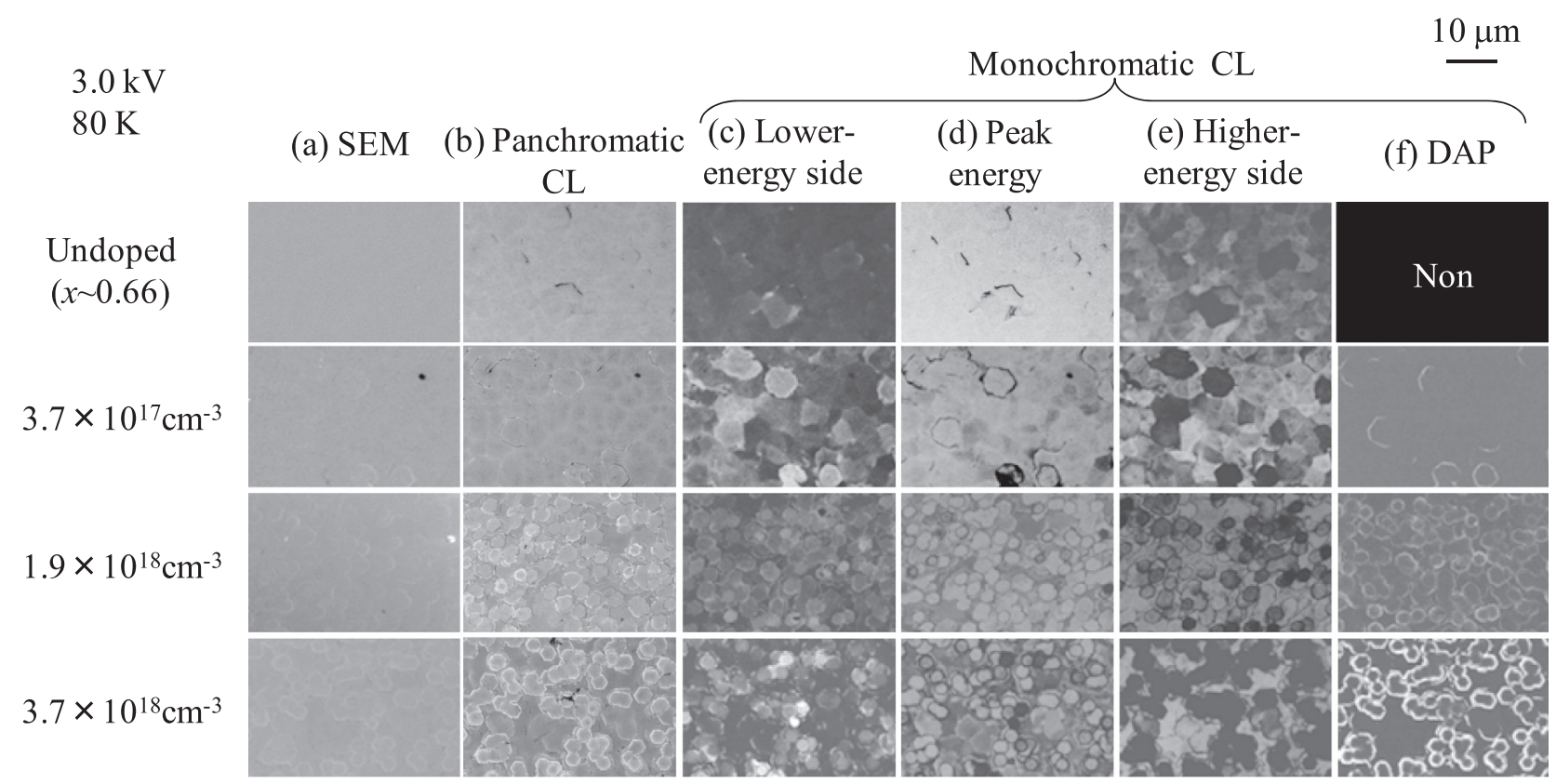

FIG. 3. (a) SEM images; (b) panchromatic CL images; monochromatic CL images obtained at the (c) lower-energy side, (d) peak energy, and (e) higherenergy side of the NBE emission; and (f) DAP emission taken from nominally undoped $\mathrm{Al}_{0.66} \mathrm{Ga}_{0.34} \mathrm{~N}$ and $\mathrm{Si}$-doped $\mathrm{Al}_{0.61} \mathrm{Ga}_{0.39} \mathrm{~N}$ epitaxial layers with various $\mathrm{Si}$ concentrations at $80 \mathrm{~K}$. 

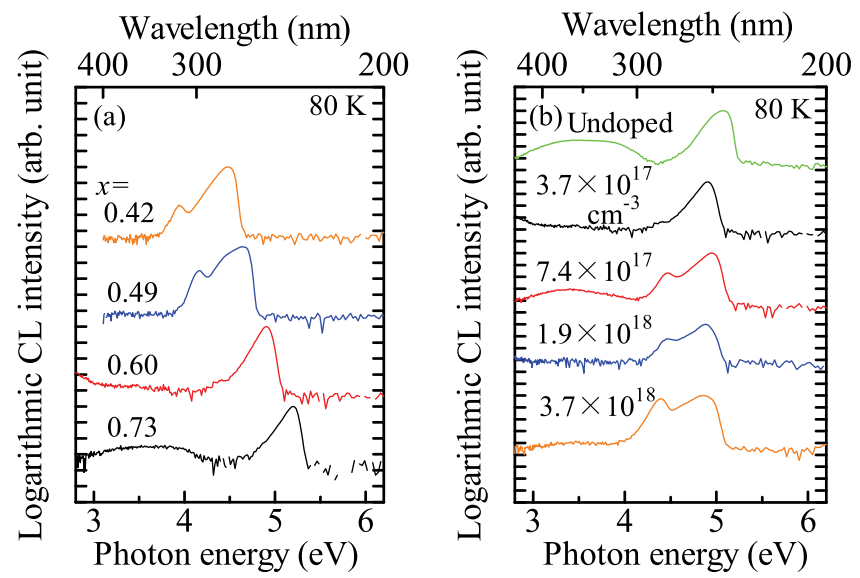

FIG. 4. Logarithmic CL spectra taken at $80 \mathrm{~K}$ from the Si-doped AlGaN epitaxial layers with (a) different relative $\mathrm{Al}$ content and (b) different $\mathrm{Si}$ concentration.

$0.54,0.47$, and $0.50 \mathrm{eV}$, respectively. Those for the $\mathrm{Si}$-doped AlGaN epitaxial layers with $\mathrm{Si}$ concentration of 3.7, 7.4, 19, and $37 \times 10^{17} \mathrm{~cm}^{-3}$ were $0.50,0.42,0.48$, and $0.47 \mathrm{eV}$, respectively. These indicate that the energetic distances are almost constant against both relative $\mathrm{Al}$ content and $\mathrm{Si}$ concentration. Figure 5 shows the acceptor energy level $\left(E_{A}\right)$ as well as the conduction band edge $\left(E_{c}\right)$, the valence band edge $\left(E_{v}\right)$, and the ionization energies of shallow donors $\left(E_{D}{ }^{0}\right)$ as functions of relative $\mathrm{Al}$ content $(x)$. The parameter sets and calculation procedure are the same as in Ref. 16, except for the band gap of $\mathrm{GaN}$ at $0 \mathrm{~K}\left(E_{g} G a N\right)$ and the band

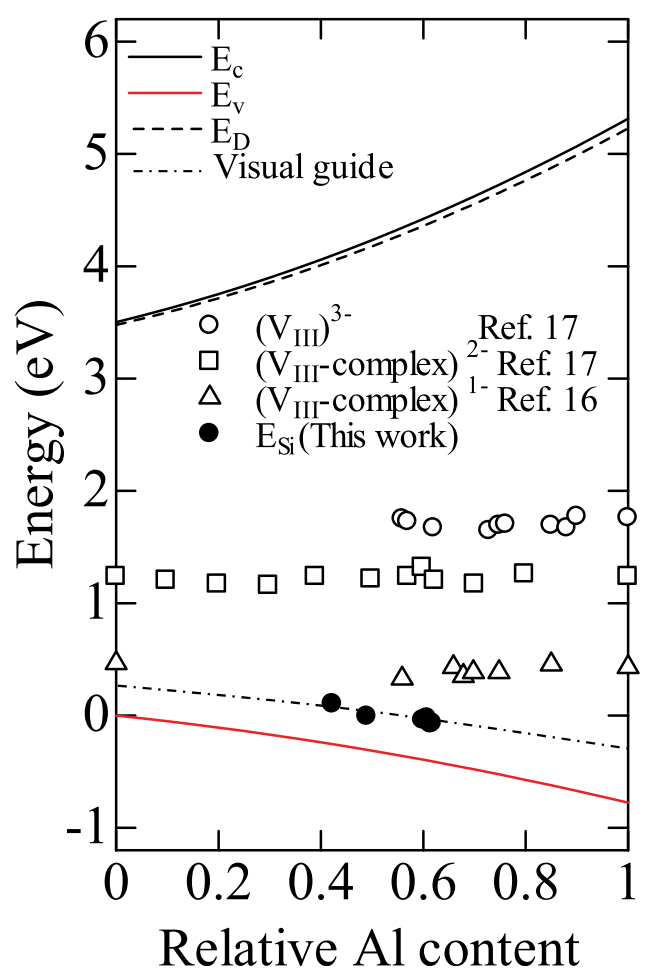

FIG. 5. Acceptor energy level $E_{A}$ of the AlGaN epitaxial layers with different relative $\mathrm{Al}$ content and $\mathrm{Si}$ concentration, which was calculated by using the same parameters and procedure as those described in Ref. 14, except for the band gap parameters. The deep acceptor energy level $E_{A}$ associated with $\mathrm{V}_{\mathrm{III}}$-complexes in Ref. 14 and Ref. 16 is also plotted together with $E_{c}, E_{v}$, and $E_{D}{ }^{0}$ for comparison. gap of AlN at $12 \mathrm{~K}\left(E_{g_{-} A l N}\right)(3.503$ (Ref. 1) and $6.089 \mathrm{eV}$, (Ref. 2), respectively). Deep acceptor energy levels associated with $\mathrm{V}_{\mathrm{III}}{ }^{3-}$, $\left(\mathrm{V}_{\mathrm{III}}{ }^{- \text {complex }}\right)^{2-}$, and $\left(\mathrm{V}_{\mathrm{III}^{-}} \text {-complex }\right)^{-}$ reported in Refs. 16 and 17 are also shown in Fig. 5. Note that these values were obtained at room temperature. $E_{A}$ estimated from the observed Si-related DAP emission was completely different from that for $\mathrm{V}_{\mathrm{III}^{-}}$-complexes. The behavior of DAP emission in relation to relative $\mathrm{Al}$ content was also different, where $E_{A}$ estimated from Si-related emission tended to change along the valence band edge in accordance with relative $\mathrm{Al}$ content. In contrast, $E_{A}$ for the $\mathrm{V}_{\mathrm{III}}$-complexes describes a horizontal line in the entire range of relative Al content. These results indicate that the origin of local DAP emission related to $\mathrm{Si}$ is completely different from that for $\mathrm{V}_{\mathrm{III}}{ }^{- \text {complexes. }}$

Figures 1(c)-1(f) show monochromatic CL images of the $\mathrm{AlGaN}$ epitaxial layers with different relative $\mathrm{Al}$ content taken at the lower-energy side at half maximum, at the peak energy, at the higher-energy side at half maximum of the NBE emission, and at the peak energy of DAP emission, respectively. Figures 3(c)-3(f) show monochromatic CL images of AlGaN epitaxial layers with different Si concentration taken at the same aforementioned energies. All images were obtained at $80 \mathrm{~K}$ at positions identical to those for the corresponding SEM images. All monochromatic CL images in (c), (d), and (e) in Figs. 1 and 3 show small grains and/or hillocks with a diameter of several micrometers, and each domain has a different emission energy. The monochromatic CL maps obtained at energies lower and higher than the peak energy were almost complementary. Inhomogeneous emission energy distribution was observed even within the hillocks. A similar distribution of emission energy in undoped $\mathrm{AlGaN}$ epitaxial layers with relative $\mathrm{Al}$ content below 0.42 was reported. Neuschl et al. observed lower energy emission at non-c-oriented side facets of hillocks in AlGaN epitaxial layer. ${ }^{18}$ This behavior is explained by different incorporation of $\mathrm{Al}$ atoms at different facets. Pinos et al. reported that the potential variations were clearly observed in samples with lower relative $\mathrm{Al}$ content and were attributed to Ga-rich regions close to grain boundaries or atomic layer steps. ${ }^{13}$ In our observations, all samples except the AlGaN epitaxial layer with relative $\mathrm{Al}$ content of 0.73 showed the same trend in terms of potential variation, where lower energy emission was observed at hillock edges, especially in samples with low relative $\mathrm{Al}$ content. In contrast, the $\mathrm{AlGaN}$ epitaxial layer with relative $\mathrm{Al}$ content of 0.73 , which contained fewer hillocks, showed a rather small potential fluctuation likely originating from grains, but no characteristic emission at grain boundaries. The details of the energy difference due to potential fluctuation in these samples will be discussed elsewhere.

Next, we focus on the distribution of Si-related DAP emission. DAP emission related to Si concentration appeared locally at hillock edges (Fig. 3(f)). ${ }^{14}$ No DAP emission was observed in the undoped AlGaN epitaxial layer, despite the presence of surface hillocks. Local DAP distribution was also observed in the AlGaN epitaxial layers with low relative $\mathrm{Al}$ content but not in those with high relative $\mathrm{Al}$ content $(>0.73)$ in which few hillocks were observed. This confirms the hypothesis that the local DAP emission is strongly 
related to both the concentration of Si dopant and the density of hillock structures. Figures 6(a) and 6(b) show SEM and monochromatic CL images obtained at the DAP emission energy of AlGaN with Si concentration of $3.7 \times 10^{18} \mathrm{~cm}^{-3}$ and 0.61 relative $\mathrm{Al}$ content, respectively. The sample was inclined to the surface normal at an angle of $45^{\circ}$. The horizontal lines indicate the surface of the Si-doped AlGaN layer and the interfaces between the Si-doped AlGaN layer and the AlGaN IML, between the AlGaN IML and the AlN layer, and between the AlN layer and the sapphire substrate. Clearly, the local DAP emission observed at the surface hillock edges were also observed deep in the Si-doped AlGaN layer (indicated by white arrows), but not in the AlGaN IML. The DAP emission area was inclined with respect to the c-plane. The inclination angle was difficult to estimate precisely because of electron penetration and carrier diffusion inside the sample; however, the appearance was similar to the bundled dislocations in $\mathrm{AlGaN}$ epitaxial layers grown with lateral coalescence through $\mathrm{SiN}_{\mathrm{x}}$ nanomasks. ${ }^{5}$ Our surface SEM images taken in panchromatic mode also showed dark hillock edges (such as in Fig. 3(b)), indicating the presence of defects at hillock edges. These results indicate that the high density of dislocations bundled at the hillock edges is related to the observed local DAP emission. As mentioned above, while the hillocks observed in our experiments had at least two origins, $E_{A}$ of the local DAP emission at hillock edges showed the same trend in both cases. In previous reports, it was reported that in III-nitrides grown by epitaxial lateral overgrowth, growth facets acted as sources of preferential incorporation of impurities and as sources of internal strain. ${ }^{19}$ Also, the island boundary regions contained a large number of dislocations. ${ }^{5,20}$ In addition, the facet edges in our $\mathrm{AlGaN}$ epitaxial layers tend to be Ga-rich regions, and thus a local strain field is introduced at the coalescence boundary. Therefore, it is likely that impurities and/or point defects are concentrated locally and exhibit peculiar properties.

$\mathrm{Si}$ is the impurity that most readily incorporates into those facet regions. SIMS measurements confirmed that the concentrations of $\mathrm{O}$ and $\mathrm{C}$, which are some possible unintentional impurities, remained almost constant with increasing $\mathrm{Si}$ concentration. This result also supports the role of $\mathrm{Si}$ impurities in the acceptor. $\mathrm{A}_{\mathrm{III}}-\mathrm{Si}_{\mathrm{III}}$ complex is one of the candidates for an explanation of Si-related DAP emission at highly dislocated and/or strained regions, ${ }^{14,21}$ the other being

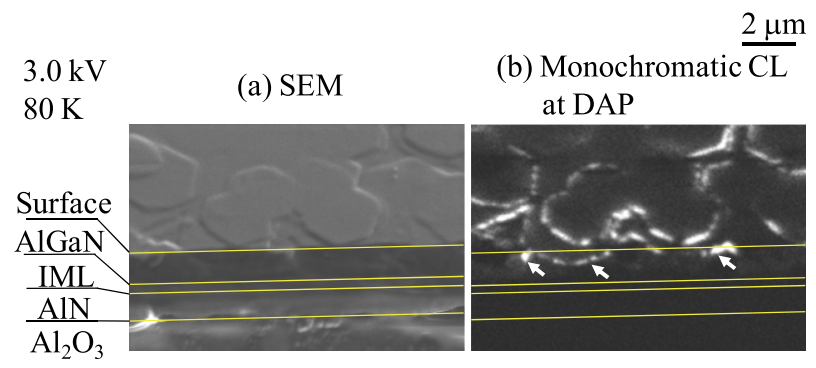

FIG. 6. (a) SEM images and (b) monochromatic CL images obtained at the DAP emission energy. The sample was inclined to the surface normal at an angle of $45^{\circ}$. Horizontal lines indicate the surface and the interfaces in the Si-doped AlGaN epitaxial layer. White arrows in (b) indicate DAP emission areas inside the sample.
$\mathrm{Si}_{\mathrm{N}}$ acceptors. $\mathrm{Si}_{\mathrm{N}}$ is considered to have an energetically unfavorable configuration in unstrained $\mathrm{GaN}$ compared to $\mathrm{Si}_{\mathrm{Ga}}$ donors, but the $\mathrm{Si}_{\mathrm{N}}$ configuration is likely to be present in materials under tensile strain. ${ }^{22}$ The binding energies of $\mathrm{Si}_{\mathrm{N}}$ in wurtzite $\mathrm{GaN}$ and wurtzite AlN were calculated to be about 200 and $200-450 \mathrm{meV}$, respectively. ${ }^{23}$ An acceptor binding energy of $224 \mathrm{meV}$, which is strongly correlated with Si doping, was determined empirically for Si-doped GaN. ${ }^{24}$ These values can account for our acceptor energy levels depending on relative $\mathrm{Al}$ content. The presence of such unstable defects is a likely explanation of why DAP emission related to Si doping occurs locally at highly dislocated and/or strained hillock edges. Three-dimensional surface structures such as hillocks facilitate the introduction of local self-compensation centers in AlGaN epitaxial layers with increasing Si concentration, resulting in low Si doping efficiency at high Si concentration. In other words, the suppression of such three-dimensional structures is expected to at least partially improve the doping efficiency at low $\mathrm{Al}$ content and high Si concentration.

\section{SUMMARY}

In summary, we performed CL mapping of the spatial distribution of luminescence in Si-doped AlGaN epitaxial layers with different relative $\mathrm{Al}$ content and $\mathrm{Si}$ concentration. As a result, it was found that surface hillocks in Si-doped AlGaN epitaxial layers developed with decreasing relative Al content, as well as with increasing $\mathrm{Si}$ concentration. At least two origins of hillocks were suggested, namely the relaxation of residual strain and the anti-surfactant effect of the Si dopant. The hillocks induced surface roughening, and the compositional fluctuation and local DAP emission at hillock edges in AlGaN epitaxial layers was enhanced irrespective of the origin of the hillocks. The intensity of local DAP emission was found to be related to Si concentration as well as to hillock density. CL observations at the detection energy of DAP emission confirmed that the DAP emission areas were observed inside of the samples. The shapes of the DAP regions were similar to those of bundled dislocations observed at coalescence regions of island growth in AlGaN epitaxial layers through $\mathrm{SiN}_{\mathrm{x}}$ nano-masks, indicating facet growth and suggesting that local DAP emission was related to accompanying dislocations concentrated at hillock edges. $E_{A}$ estimated from emission energy could not be explained by $\mathrm{V}_{\mathrm{III}}$-complex-related levels as previously considered. Possible candidates for acceptors in the observed DAP emission, which was closely related to both $\mathrm{Si}$ concentration and hillock edges including large deformations, are a $\mathrm{V}_{\mathrm{III}}-\mathrm{Si}_{\text {III }}$ complex or $\mathrm{Si}_{\mathrm{N}}$, which are unfavorable in ordinary III-nitrides.

\section{ACKNOWLEDGMENTS}

This work was supported by JSPS KAKENHI Grant Number 25420288.

${ }^{1}$ B. Monemar, Phys. Rev. B 10, 676 (1974).

${ }^{2}$ M. Feneberg, R. A. R. Leute, B. Neuschl, K. Thonke, and M. Bickermann, Phys. Rev. B 82, 075208 (2010). 
${ }^{3}$ P. Cantu, F. Wu, P. Waltereit, S. Keller, A. E. Romanov, U. K. Mishra, S. P. DenBaars, and J. S. Speck, Appl. Phys. Lett. 83, 674 (2003).

${ }^{4}$ S. Tanaka, M. Takeuchi, and Y. Aoyagi, Jpn. J. Appl. Phys., Part 2 39, L831 (2000).

${ }^{5}$ O. Klein, J. Biskupek, K. Forghani, F. Scholz, and U. Kaiser, J. Cryst. Growth 324, 63 (2011).

${ }^{6}$ Y. Taniyasu, M. Kasu, and N. Kobayashi, Appl. Phys. Lett. 81, 1255 (2002).

${ }^{7}$ Y. Shimahara, H. Miyake, K. Hiramatsu, F. Fukuyo, T. Okada, H. Takaoka, and H. Yoshida, Jpn. J. Appl. Phys., Part 1 50, 095502 (2011).

${ }^{8}$ Y. Shimahara, H. Miyake, K. Hiramatsu, F. Fukuyo, T. Okada, H. Takaoka, and H. Yoshida, Appl. Phys. Express 4, 042103 (2011).

${ }^{9}$ A. Uedono, K. Tenjinbayashi, T. Tsutsui, Y. Shimahara, H. Miyake, K. Hiramatsu, N. Oshima, R. Suzuki, and S. Ishibashi, J. Appl. Phys. 111, 013512 (2012).

${ }^{10}$ H. Murotani, Y. Yamada, H. Miyake, and K. Hiramatsu, Appl. Phys. Lett. 98, 021910 (2011).

${ }^{11}$ S. Kurai, K. Shimomura, H. Murotani, Y. Yamada, H. Miyake, and K. Hiramatsu, J. Appl. Phys. 112, 033512 (2012).

${ }^{12}$ H. Murotani, T. Saito, N. Kato, Y. Yamada, T. Taguchi, A. Ishibashi, Y. Kawaguchi, and T. Yokogawa, Appl. Phys. Lett. 91, 231910 (2007).

${ }^{13}$ A. Pinos, V. Liuolia, S. Marcinkevičius, J. Yang, R. Gaska, and M. S. Shur, J. Appl. Phys. 109, 113516 (2011).
${ }^{14}$ S. Kurai, F. Ushijima, Y. Yamada, H. Miyake, and K. Hiramatsu, Jpn. J. Appl. Phys., Part 1 52, 08JL07 (2013).

${ }^{15}$ K. Kanaya and S. Okayama, J. Phys. D: Appl. Phys. 5, 43 (1972).

${ }^{16}$ N. Nepal, M. L. Nakarmi, J. Y. Lin, and H. X. Jiang, Appl. Phys. Lett. 89, 092107 (2006).

${ }^{17}$ K. B. Nam, M. L. Nakarmi, J. Y. Lin, and H. X. Jiang, Appl. Phys. Lett. 86, 222108 (2005).

${ }^{18}$ B. Neuschl, K. J. Fujan, M. Feneberg, I. Tischer, K. Thonke, K. Forghani, M. Klein, and F. Scholz, Appl. Phys. Lett. 97, 192108 (2010).

${ }^{19}$ F. Bertram, T. Riemann, J. Christen, A. Kaschner, A. Hoffmann, C. Thomsen, K. Hiramatsu, T. Shibata, and N. Sawaki, Appl. Phys. Lett. 74, 359 (1999).

${ }^{20}$ A. Sakai, H. Sunakawa, and A. Usui, Appl. Phys. Lett. 73, 481 (1998).

${ }^{21}$ S. F. Chichibu, H. Miyake, Y. Ishikawa, M. Tashiro, T. Ohtomo, K. Furusawa, K. Hazu, K. Hiramatsu, and A. Uedono, J. Appl. Phys. 113, 213506 (2013).

${ }^{22}$ A. L. Gurskii, E. V. Lutsenko, V. M. Zelenkovskii, T. V. Bezjazychnaja, V. N. Pavlovskii, V. Z. Zubialevich, B. Schineller, O. Schön, G. P. Yablonskii, and M. Heuken, Phys. Status Solidi C 0, 425 (2002).

${ }^{23}$ F. Mireles and S. E. Ulloa, Phys. Rev. B 58, 3879 (1998).

${ }^{24}$ J. Jayapalan, B. J. Skromme, R. P. Vaudo, and V. M. Phanse, Appl. Phys. Lett. 73, 1188 (1998) 